\title{
Linguistic Representation Of Sports Women In Pakistani English Newspapers
}

\author{
Qaisar Khan \\ Department of English \\ University of Malakand \\ Maria B. Shahid \\ \& \\ Sohni Ihsan \\ Department of English \\ Fatima Jinnah Women University
}

\begin{abstract}
Women are integral to social progress and development. They participate in all walks of life and contribute their fair share for the overall good. Globally, they have been contributing in sports and have brought a positive change in the outlook of societies in favour of gender balance. Conversely, primitive and less developed societies restrict women to domestic sphere and discourage them to participate in public life. They also view sports as masculine domain and frown upon the participation of women in any sports. In Pakistan, the situation is no less different and with a predominantly patriarchal social structure, the country does not cater to the needs of female players in provision of facilities and infrastructure. Despite the growing number of renowned female players, the attitude of the people in general and the government in particular is biased and discriminatory. This study intends to qualitatively analyze newspaper reports through the application of linguistic tools. The reports are purposively selected from published Pakistani English newspapers about women sports available online. The findings reveal that women are underrepresented and narrowly described for their achievements. The study further reveals that they are faced with the challenge to overcome conservative cultural narrative that discourages female sports.
\end{abstract}

Keywords: Female Sports, Gender Disparity, Gender Bias, Socialization.

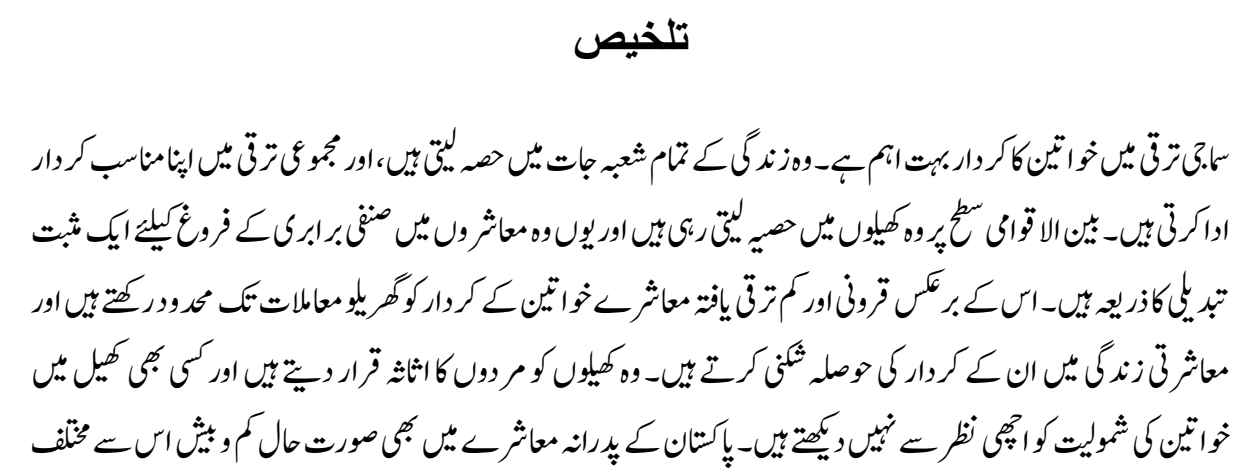




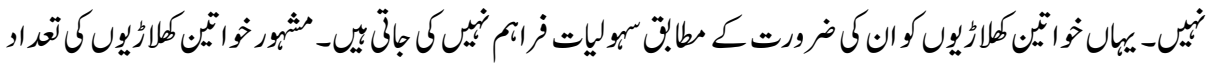

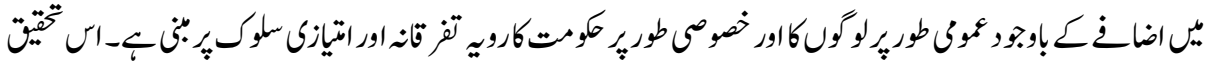

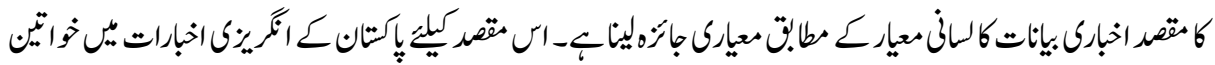

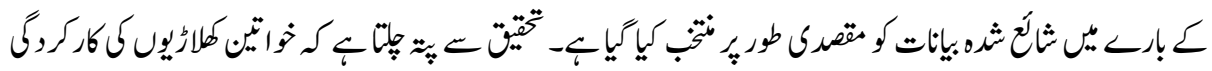

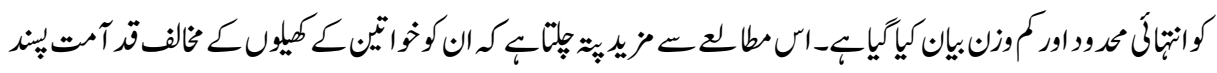

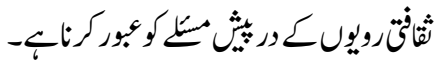

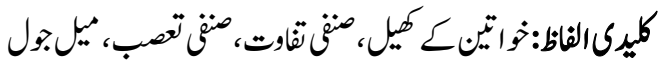

\section{Introduction}

Sports activities are integral to all societies. It is defined as 'a human activity capable of achieving a result requiring physical exertion and/or physical skill, which, by its nature and organization, is competitive and is generally accepted as being a sport' (McCue \& Kourouche, 2010, p. 131). More recently, sports events are globally institutionalized for both men and women. With rare incidence of mixed events, male and female sports activities are regularly held and reported in newspapers at all levels. In Pakistan, female sports events and players are also given space in print media. However, their coverage is minimal comparatively. The description of sports women is less vibrant and more stereotypical that project and reinforces them as less active, weak and non-athletic. As a dominant agent of socialization, media in general and newspapers in particular therefore do not effectively contribute in promoting women sports and motivating them to take active part in it (Sage \& Furst, 1994). The purpose of the current study is to examine selected Pakistani newspapers in English language and to highlight description of female players with a view to establish the seminal role of language in preserving, reinforcing and thus perpetuating gender biased identities with less space for women in the public domain. The argument of the study is based on the influence of media in public opinion formation, its role in framing people's perceptions, beliefs and attitudes mainly through linguistic expressions supported by visual representations.

\section{Literature Review}

Language is an integral part of any culture, which provides an insight into its characteristics. It is through language that most of the culture is expressed. In turn, culture is a collection of attitudes and behaviours which determines and decides the status of its members. The members of any culture, in general, may be divided into male and female. Biological factors do play their role in the division but it is the social experience and the socialization process, which assign certain tasks to male and female. As a non- 
instinctive but natural ability, human language is a primary vehicle of giving expression to thoughts, ideas and emotions. More specifically, language shapes thoughts and ideas in words and sentences that then constitute an important ingredient of culture (Khan, Sultana, Bughio \& Naz, 2014).

As significant contributor to the socialization process, language is loaded with culture specific teachings and thus a carrier of the overall cultural patterns including norms, values, customs, and traditions. Socialization is, according to Karp \& Yoels (1993:45), 'the process through which individuals learn what society expects from them'. In other words, they view it a means of transmitting culture over generations. To Hudson (1987: 42-43), the language 'which a child learns is closely related to the concepts he learns as part of his socialisation' He further adds that we learn and acquire many concepts through language mainly through formal schooling. Lips (1988:231) also identifies language as a key source of information and of 'social pressure with respect to gender roles'.

With reference to linguistic determinism and the influence of language on thought, Hudson (1987) observes that its influence on our thought is considerable. In support of his argument, he refers to Whorf (1940:96-105) who is of the view that grammar 'is not merely a reproducing instrument for voicing ideas but rather is itself the shaper of ideas'. To him, it serves as a guide of our mentally faculty that enables us to analyse our impressions. Similarly, Trudgill (1980) argues that language serves as a network of categories around which a speaker constructs the world. A language therefore has the power to influence and thus condition our worldview and society at large. With reference to Sapir-Whorf hypothesis, Ji, Zhang \& Nisbett (2004) are of the view that the hypothesis relates to heated debate over culture, language and cognition. To them, habitual thinking of people can be influenced by language and that culture and language cannot be separated. Likewise, Rahman (2000) also finds language of seminal importance in interpreting the world through language and the categories it provides.

With particular reference to gender, Lips (1988) asserts that masculinity and femininity are conceived by us in the language of opposites. Further, Stockard \& Johnson (1980:3-4) comment that '....all human languages make a definite distinction between the sexes, and all societies use sex as a basis for assigning people to different adult roles'. They are of the view that male dominance is transmitted over generations through language mainly in the context of religion and mass media. In this way, we are defined, identified and delimited in our ability to think beyond our linguistic repertoire. They therefore are of the view that 'humans are both creators and victims of culture'.

The role a language plays in the process of gender socialization has also been dealt with in detail by social scientists. Language is not 'sex-neutral' and it 'divides, separates, and differentiates women and men' (Doyle \& Paludi, 1991:214-216). Further, the contents of 
language, according to them, reinforce and perpetuate sexist ideology. Commenting on the role of language in the context of school textbooks, Naureen Durrani (2008) holds that they serve as national narrative attempting to portray the best and the ideal worthy of emulation. Consequently, any trait or quality, attribute or action valued by the nation is reflected in these textbooks. In a similar fashion, gender also form active part of the narrative. The linguistic expressions and the gendered meanings they carry with them are therefore pivotal in the process of socialization (Khan, et al. 2014). Newspapers also enjoy wide recognition and are favourably received by the masses. As representative of the national aspirations and ideology, they also attempt to construct gender identities through dress, work and sphere of activity.

Like all other forms of specialized discourses, media has its own unique language. Discourse is understood in different ways. Generally, discourse implies the manner in which members of society communicate. At deeper level, it is symbolic of the unique system of our thoughts and beliefs that determine how the world around us is understood and interpreted. Media discourse has various forms and manifestations and people in the field of media use it in print, audio and visual form such as in newspapers, radio, television and internet etc. To comprehend media discourse as various means of communication, two primary types including written and spoken communication are important. As referred to earlier, the written texts are primarily in the form of newspapers and magazines wherein the published articles are instances of discourse while advertisements too constitute a form of discourse to some extent. As far as spoken form of media discourse is concerned, it occurs in the media mainly on radio and television that serve as the major means of broadcasting news and views. These apart, Internet has also emerged as a potent vehicle of media discourse where instances of both written and spoken form are found.

We filter the world around us through different lenses. Some individuals value sociopolitical perspective where they view and examine the system of decision making at societal level. Other individuals have a tilt towards looking at the economic aspects of the world they see and have therefore a taste for economic discourse. Likewise, some others are less interested in profit/loss or right/wrong and prefer the otherwise less material aspects of things like entertainment or discourse related to sports. Media discourse may best be understood as the sum total of the concepts we use for processing available information that is of major concern.

Media language is of considerable interest to a linguist as it read and heard in by people in large proportion around the clock. Due to its irresistible existence in our everyday lives, media language permeates our attitudes. It reflects as well as shapes the way we interpret the world. From linguistic point of view, it is important to know how language is employed in various forms like articles and advertisements that project the writer or 
advertiser on the one hand and the assumed reader on the other. Similarly, the spoken discourse on radio or television also has much to discern with reference to the speaker and the hearer.

As an important institution, newspaper media reflects, reinforces and thus perpetuates culture, politics, and the particular social world in which it operates. It importance for a linguist is to ascertain the level and extent of its revelations about and its contribution to the character of a society. To this end, systems of interrelated lexical, grammatical and phraseological means are at work with the manifest function of informing, entertaining and instructing readers. Owing to the diverse interests of readers, the contents of newspaper are not rigorously informational but may be intended to inject evaluative material, views and opinions of the reporters and editors. Although theoretically informational, newspaper material tend to influence readers at various levels. As a propaganda machine, it includes evaluative connotations at socio-political, economic and religious or moral matters relevant to the readers.

With particular reference to the culture of sports among women and their representation in newspapers, it is important to highlight that they had historically been denied active participation in particularly outdoor adventures and this mindset still prevails in the less developed countries. Globally, access of women into the domain of sports continues to be a Challenge as particular physical traits such as physical strength, competitiveness, Aggression, and determination are considered the possessions of men only (Hargreaves, 1994; Van Ingen, 2003; Vertinsky, 2004). In his article, Young (1990) examines the socialization of women and how femininity is associated with being timid, fragile, graceful, soft and taking up as little physical space as possible. This mindset has historically discouraged women to wear sports shoes traditionally reserved for men. When women do decide to enter the 'contested terrain' of sports there are a multitude of challenges that exist, including the sexualisation of their bodies (Burroughs, Ashburn \& Seebohm, 1995). The role of media and progressive coverage of women in sports is significant because it is widely acknowledged, read and watched across society and has a say in informing our knowledge, opinions and attitudes. Healthy projection of sports women in media has a considerable impact on their future development and contribution to society.

As an integral part of media information and also a commercialized phenomenon, media has a profitable symbiotic relationship with sports. Due to its wider following, sports news also contributes in the promotion of newspapers and magazines; boost television ratings and attract sponsors. Coverage of sports news is also key to attracting people towards different sports events; to arouse the interest of the public and thus adds to the demand for various sports. At the dawn of the $21^{\text {st }}$ century, the sports and popular media have become indispensible for each other for promotion. In other words, the one cannot thrive without the support of the other. 
With reference to gender representation, Hall (1997) opines that it essentially is linked with the process through which we produce and exchange meanings in a culture. During the process, we employ language signs or images that represent things. The current study is specific to the representation of sports women in newspapers. While to Hall (1997), representation implies the use of language to meaningfully present or portray the world to other people. Thus, meaning is constructed through language that also develop, shape and frame reality. As is observed by Talbot, Atkinson and Atkinson (2003), language is vital to articulate reality which in turn has far reaching implications and this is also true in the context of media language.

In a similar way, Lippmann (1946) presents several illustrations to establish the insignificant relationship between the world's factual features and the belief system that people entertain about that world. He states that the depiction of events in media influence the way readers tend to interpret the reality. We are guided by that particular mindset that pervades the media language that subsequently contributes in the way we act and react after exposure to the reported events. During this mental process, it is noted that the mental meaning-making may not truly correspond to what is right and true.

Similarly Thomas (1823 as cited in Greer, 2001:57) corresponds with Lippmann's view and states that "the press is the best instrument for enlightening the mind of man, and improving him as a rational, moral and social being'. He acknowledges the imprints of media in the way we present ourselves rationally, morally or socially. In a sense, the influence of media on our lives is multifaceted and we are not necessarily conscious about it all the time. The same also applies to the way women are highlighted and portrayed that guides the way we perceive and interpret the world of women. Parry and Karam (2001) also support the influence of media but they add that it has, over the years, contributed in imparting patriarchal and ideological messages. Likewise, Ashford and Clifton (2005) argue that although constituting over fifty percent of the world's population, women are under-represented in the media. It incidence is equally relevant to sports women. Like other fields of human enterprise, sports too are portrayed as a masculine domain that tends to discourage women to actively look forward to sports as a profession. Owing to the global acceptance and passion for sports, the underrepresentation impact women in other domains too. Objective analysis of an everyday newspaper particularly in developing countries like Pakistan reveals that politics and economics are controlled by men as decision makers and they have also succeeded in reaching zenith heights in sports.

However this is not all. Van Zoonen (1994) observes that those women who reach the world of media are represented in a biased manner; are subjected to their physical beauty and subjugated to men as husbands, father and sons. Additionally, they are idealized for their submissive nature and male-dependent demeanor. These portrayals and images in 
turn create, preserve and reinforce our attitudes. Rogers and Dearing (1988) also support the significance of various media like newspaper, radio and television in shaping or influencing public opinion. For instance, the depiction of a sportswoman as a sex object or reference to her beauty implies that such traits are to be valued more in comparison to strength, power and skill that are basic to a person in any sport. In other words, a sportsman is idealized for his power and energy while such qualities are of lesser concern to the world of media in the context of sports for women.

Greer (1999:22) is of the view that 'newspaper is one of the most efficient forms of mass communication ever created, huge numbers of people read and trust newspapers'. Therefore, it is important to examine the language employed in reporting and to devise strategies to make media linguistic expressions gender balanced and accommodative. Women need to be represented in a way that they earn respect from the other gender and inculcate positive attitudes among other women about sports. Historically, women have lagged behind in competing with men particularly in sports. One reason is also attributed to less or no space for them in media. It is however important to note that in the recent years, they have found various sports to display their talent and to impress upon the patriarchal mindset that they too have abilities and can question their traditional idealization as emotional, weak and dependent. The role of media is of material value in trending women sports in the recent years and the current research study therefore also analyses the influence that media has had in promoting women in sport.

Overall, women representation is more negative than progressive in sports with notable exceptions of those who excel in their sport. In many instances, we know very little about even those women who have achieved a lot in comparison to average male achievers in various sporting events. Likewise, many women although actively engaged in sports receive less public and media encouragement. It implies that public reaction and media trends reinforce each other. Public opinion is shaped and reshaped by media images and as the current media trend favours men so do people in general favour men in sports.

\section{Methods and Procedure}

Through a qualitative research design, the study focuses on the use of words and expressions in the context of women sports news. It analyses particular linguistic terms used for women through linguistic analysis: Linguistic analysis can be used to describe the unconscious rules and processes that speaker of a language uses to construct reality. Linguistic analysis is more about analyzing the language and about extracting meaning of the given text. The method of linguistic analysis is employed to dig out the hidden meanings with cultural connotations used for sports women in newspapers. 
The study is based on the collection of 200 newspaper items, reports and interview extracts of female players out of which 20 were purposively selected from online archives of English newspapers published in Pakistan including The daily time, The Nation, Dawn, The News and The Express Tribune. Owing to the scarcity of women sports news particularly at local level, the researchers considered relevant reports available in the selected newspapers in the time period of 2002 to 2014. For the purpose of the study, Google and Yahoo search engines were employed.

The linguistic tools used during analysis of the data include tone that implies the attitude the writer conveys about the paragraph's subject. Tone is a literary compound of composition, which encompasses attitudes toward the subject and toward the audience implied in a literary work. It may be positive, negative or neutral. Sexism was coded based on the five gender characteristics identified by Wensing and Bruce (2003) including gender marking; heterosexuality; femininity; infantilization and nonsport related reports. Another linguistic tool made use of in the study is presupposition that implies the way in which language can assume a particular meaning without directly asserting it. A presupposition is background belief, relating to an utterance that must be mutually known or assumed by the speakers and addressee for the utterance to be considered appropriate. Also important to the analysis are lexical words, also known as content words that have concrete meaning. These words refer to things, actions, descriptions, people or other ideas that have more than just a grammatical usage. Lexical categories in English include nouns, most verbs, adjectives and many adverbs.

With the help of linguistic tools, the sports discourse is analyzed to highlight the representation of women and the scope of such activities. An attempt is also made to bring forth popular perceptions and stereotypes in the presentation. Each news item is carefully examined to highlight the linguistic tools and the employment of vocabulary. The selected news items are represented in the analysis by their authors or reporting agencies.

During the study, a collection of the newspaper reports was made and then it was thematically organized according to the scope of the study. The collected data was then analyzed in a thematic manner to bring forth and highlight the way women were represented. The findings of the study were discussed in the results and discussion section followed by a conclusion and summary at the end.

\section{Data Analysis and Discussion}

The analyses of selected news reports and documentaries published in the Pakistani English newspapers reveal variety of themes. The reports depict women sports and 
female players at national level. News items related to local or provincial level sports events and tournaments are rare. Majority of the reports are performance based related to commendable achievements of sports women at national and international level sports. Alongside, a recurrent theme of lack of opportunities and infrastructure for female sports is also deplored. The lack of attention of government to provide funds and facilities is also noticed.

During the analysis of the reports, some of news items are marked for gender bias (Eastman \& Billings, 2000). No doubt, gender disparity in sports activities in the country is an open secret, the predominantly male sports reporters and editors also reinforce the situation (Miloch, Pedersen, Smucker \& Whisenant, 2005). Instead of deploring the lack of infrastructure for women sports, they tend to report in a way to create the impression that major sports including cricket, hockey and football etc are masculine in nature and women are less likely to indulge in them. Further, the same mindset also justifies the national indifference to women sports. Gender bias is also noticed when despite the reported international level achievements of women players do not convince the reporters to plead gender balance and to criticize the government for not providing more opportunities for them (Eastman \& Billings, 2000).

At another level, the news items have positive overtones in dealing with the achievements of the reported players but in many instances these glorious moments are shrouded in the miserable playing environment for women. Every time a female player is praised for her indefatigable spirit, she is at the same time projected in a highly demotivating environment that reduces the chances of young readers to aspire for the same. It is also noted that female players do not find any platform to voice their grievances and problems. In order to be heard, they have to perform well and only then they get reported where most of their time is spent in deploring the playing environment instead of celebrating their achievements. Further, the news reports project the achievements of the players as exceptional to the women specie. Success stories are rarely generalized to womenfolk that reinforce the gendered perception of power and energy as masculine possessions. Gender bias in news reports is visible in statement where sports are described as masculine domain with less or no space for women (Eastman \& Billings, 2000). For instance, while describing the formation of national cricket team, the report states, 'Generally speaking, international cricket is traditionally a male-dominated sport' (Reuters, 2011). But in early January the Pakistan Cricket Board officially decided to create a national female cricket team to participate in international competitions. It creates the impression as if the Board has decided to embark upon a novel idea of allowing women to cricket ground.

In relation to the difficulties faced by female players in the field, a score of hardships are enlisted and repeated. As discussed above, the lack of attention of the government to 
facilitate female players remains at the top. This apart, reference is also made to cultural barriers shrouded in the folds of religion are also vaguely described that further reduces the chances of young players to display their talent appropriately. For instance, a reference is made to the gender-segregated cultural set up that prevents female to mix with and to be seen among men (AFP., 2013; AFP., 2008). Traditionally idealized in domestic sphere, women are less likely to get approval in public domains including playing grounds. The same theme also reverberates in the inside stories of female players. Without logical differentiation of identities, reporters frequently mix religion with culture in describing the prospects and future of women sports in the country. Such statements are made part of the sports narrative without realizing the impact of mixing facts and opinions (Reuters, 2011). In one such report, the newspaper reporter states: 'Pakistan's conservative society restricts women's participation in sporting events. They are usually barred from competing before men spectators and are only allowed to play in Islamic dress of long shirts and trousers' (AFP., 2008).

Dogmatized cultural notions dominate reporters when they describe Naseem Hamid having 'nerves of steel' (Raheel, 2013a) and overuse of the term 'female' with different sports activities. These expressions tend to isolate these players from the rest of the womenfolk as exceptionally strong and individualize them for their achievements. Further, unnecessary details are captured by reporters about the private hours of the players with a view to establish the existence of insurmountable challenges for women to enter the playing field. For instance, the reporter focuses the practicing hours of Rubab and makes her reveal, 'Whenever I go out of home or train at the swimming pool some family members or at least my grandmother remains with me' (AFP., 2004). The statement is instantly reinforced in cultural context when the reporter asserts, 'The family contingent is one concession to the strict mores surrounding women in the world's second largest Muslim country'. In yet another instance of describing a woman athlete, the reporter gives more value to assert that, 'In a country known for its conservative values which frowns upon women taking part in field events' (AFP., 2012). Likewise, a report quotes Syeda Fareeda Khannum, a Kabaddi player to have said, 'I have been sports crazy since childhood but I was never allowed by my family to attend a training camp outside college or university' (AFP, 2013b). To note, such statements are unnecessary and are less applicable to civil society. A country with low literacy, it is no wonder if people disapprove of women sports but uninformed condemnation does not necessarily negate the utility of activities.

The players reported in the newspapers display singular commitment and love for their sports. The intermittent quotes from them in the news reports point to their enthusiasm and courage never to submit or yield. At one place, Kiran, a reputed national swimmer does not feel disappointed for the lack of attention towards her achievements in swimming and expresses her hope and optimism to get noticed at some point of time. She 
has a resolve to stick to her job with the hope that she would win the people to her side (Raheel, 2013b). Conversely, some of the players are frustrated and less hopeful because of the policies For instance, the news tells that the famous athlete Naseem Hameed has left sports. The news adds, 'the most disappointing factor and the reason behind her quitting the sport was the lack of support from the government and sports authorities' (Raheel, 2013a). Such information has debilitating effects on the proponents of women sports and amateur sports women. It also strengthens the argument of gender disparity in the field of sports. Men are given more importance and funds and their sporting events are backed by the government and the society at large. It also testifies the control of power domain by the conservative and less democratic forces in the country.

Overall, the news reports are overshadowed by problems and challenges faced by women players. These include the dogmatic religion and Pakistani conservative culture which is proving to be major hurdles to accept women as players in the sports field. These women are not allowed to play in the country in front of men or to play wearing short dresses. Some players are also found financially less prosperous due to which they do not find means to survive and perform in the field. Further, they are less likely to be acknowledged and owned by the government and to admire their talents or to support them emotionally or financially. They mourn the lack of facilities and like Shahbana Akhtar the reports are ripe with the theme of, 'I gave Pakistan so much but didn't get anything back'. Many unreported women players fail to participate in events due to lack of financial support from the government and did Shabana Akhtar who could not accomplish her mission of participating in London Olympics because of lack of financial support by anyone (Hashmi, 2012). The country's resolve to promote women sports can best be described in the words of Rabia Qadir, according to whom, 'There is not a single women academy across the country' (Khan, 2012).

Nevertheless, amid the narrow narrative of women sports in the country, there are women who have won medals at national and international levels less bothered by the unavailability of resources and opportunities. They demonstrate a positive image of these sports players. They are strong and resolute to break the shackles and have challenged the conservative mindset in the country (Sports Reporter, 2014). Success stories are pouring from sports fields traditionally reserved for men such as Kabadi, swimming, racing, mountaineering, cricket, hockey etc (AFP., 2013b; Reuters, 2011). Owing to the singular display of their skill and commitment, women players in the country deserve the attention of the government to make proper provisions for their sports. The newspaper editors and reporters also need to realize their tilt in favor of covering male sports events. The reporters also need to strive for doing away with gender disparity and bias in stating facts and opinions (Eastman \& Billings, 2000). 


\section{Summary and Conclusions}

The linguistic analysis of newspaper reports was done with the aim to highlight the way sports women are represented and portrayed in newspapers. The findings revealed variety in their depiction. Predominantly, women sports were underrepresented with lack of infrastructure and opportunities for them to excel in the field. News items that reported moments of glory for the victors were more positively portrayed promising a brighter future for women sports. Also women players were shown breaking the shackles and striving hard against conservative values that attempted to reserve sports for men only (Reuters, 2011). Sexism was also recurrent in many reports showing gender bias and disparity. The findings of the study also revealed less coverage for women sports in the print media. Further, it was observed during data collection that a number of the selected items on women sports were placed at the bottom of pages or towards the end of the sport section. The choice of language was also predominantly gendered with power, energy and strength as masculine attributes. Men were more often 'powerful' and 'dynamic' while women were mostly teenagers or young girls etc.

During the analysis, it was also revealed that sports women were infantilized and portrayed in emotive terms. If women and girls' sport are ignored or infantilized, what sort of message is this sending? It was found that men dominated the sport sections in the newspapers with less or no news of female sports activities. Likewise, the researchers found many instances in which men sports at local level were reported in the newspapers. In comparison, women did not enjoy that much freedom to get reported for sports activities at district or provincial levels. Majority of news reports of female sports activities related to national and international events with a major chunk for the game of cricket that was the most popular sport in the country.

Overall, newspapers were found scarcely populated with women sports and that could be the outcome of male dominated newsrooms. Women were often invisible, and their sports endeavors trivialized and marginalized contrary to the modern democratic ideals of nonracialism and non-sexism.

To promote women sports and to encourage them to actively participate in it requires consistency and gender balance in the national narrative of sports. Intellectuals need to highlight the importance of the issue and bring it into the notice of newspaper editors. It is also imperative that we examine and challenge women underrepresentation in media that perpetuate gendered perception about sports activities. There is a need to challenge media discourse for long lasting change in attitudes. The amount of coverage for women's sports also need to be increased and it should include ethnic minorities, larger women, women with disabilities, and older women particularly at local level. The newspaper editors also need to realize the ever growing number of women in the public 
domain particularly in sports. In the light of the data collected, the fact that there are many women players that could be reported, the obvious question is: Why aren't more stories written about women's sport? The answer may not be a straightforward one. Researchers need to peep into societal attitudes and to draw the attention of journalists and editors to work for greater good by reducing gender gap in reporting.

\section{References}

AFP. (2004). Rubab Set to Become First Pakistani in Olympic Pool. Dawn. , June 24, retrieved from: http://www.dawn.com/news/362692/rubab-set-to-become-firstpakistani-in-olympic-pool

AFP. (2008). Pakistan's Female Athlete Hopes to Uphold Olympic Spirit. The Nation, August 01, retrieved from: http://www.nation.com.pk/karachi/01-Aug2008/Pakistans-female-athlete-hopes-to-uphold-Olympic-spirit

AFP. (2012). Rabia, Anum to Continue Pakistan's Lineage of Women Olympians. Dawn. , July 26, retrieved from http://www.dawn.com/news/737381/rabia-anumto-continue-pakistans-lineage-of-women-olympians

AFP. (2013a). Breakthrough Moment for Pakistan Women's Cricket. Dawn, March 08, retrieved from: http://www.dawn.com/news/791188/breakthrough-moment-forpakistan-womens-cricket

AFP. (2013b). Kabaddi, Kabaddi, Kabaddi: Pakistani Women will Play World Cup. The Express Tribune, December 01, retrieved from: http://ribune.com.pk/story/639338/kabaddi-kabaddi-kabaddi-pakistani-womenwill-play-world-cup/

Ali, S. \& Mir, S. (2013). For the Record: Woman Climber makes Pakistan Proud. The Express Tribune, May 20, retrieved from: http://tribune.com.pk/story/551934/ reaching-new-heights/

Anis, K. (2004). Kiran Smashed Highest Score in History of Women's Cricket. Daily Times, March 17, retrieved from: http://archives.dailytimes.com.pk/sport/17-Mar2004/kiran-smashes-highest-score-in-history-of-women-s-cricket

Ashford, L. \& Clifton, D. (2005). Women of Our World 2005. Population Reference Bureau. 
Burroughs, A., Seebohm, L. \& Ashburn, L. (1995). A Leso Story: A Case Study of Australian Women's Cricket and its Media Experience. Sporting Traditions, vol.12:1, pp.27-46.

Doyle, J. \& Paludi, M. A. (1991). Sex and Gender. USA: Wm. C. Brown Publisher.

Durrani, N. (2008). Schooling the 'Other': the Representation of Gender and National Identities in Pakistani Curriculum Texts. Compare: A Journal of Comparative and International Education, vol.38:5, pp.595-610.

Eastman, S. T. \& Billings, A. C. (2000). Sportscasting and Sports Reporting: The Power of Gender Bias. Journal of Sport \& Social Issues, vol.24:2, pp.192-213.

Greer, G. (1999). A New Introduction to Journalism. Chicago, IL. Juta and Company.

Greer, G. (2001). The Role of the Professional Theatre Critic in a Post-Apartheid South Africa, South African Theatre Journal, vol.15:1, pp.56-64.

Hall, S. (Ed.). (1997). Representation: Cultural Representations and Signifying Practices. Sage: Sage Publications.

Hargreaves, A. (1994). Changing Teachers, Changing Times: Teachers' Work and Culture in the Postmodern Age. Teachers College Press.

Hashmi, N. (2012). I gave Pakistan so much but didn't get anything back. The Express Tribune, July 28, retrieved from: http://tribune.com.pk/story/413876/i-gavepakistan-so-much-but-didnt-get-anything-back

Hudson, R. A. (1987). Sociolinguistics. Cambridge: Cambridge University Press.

Ji, L.-J., Zhang, Z. \& Nisbett, R. E. (2004). Is it Culture or is it Language? Examination of Language Effects in Cross-Cultural Research on Categorization, Journal of Personality and Social Psychology, vol.87, pp.57-65.

Karp, D. A. \& Yoels, W. C. (1979). Symbols, Selves, and Society: Understanding Interaction. Lippincott Williams \& Wilkins.

Khan, A. (2012). Academies Vital for Women Hockey. The Nation, January 05. retrieved from: http://nation.com.pk/sports/05-Jan-2012/academies-vital-for-women-hockey 
Khan, Q., Sultana, N., Bughio, Q. \& Naz, A. (2014). Role of Language in Gender Identity Formation in Pakistani School Textbooks. Indian Journal of Gender Studies, vol.21:1, pp.55-84.

Lippmann, W. (1946). Public Opinion, Transaction Publishers.

Lips H. M. (1988). Sex and Gender an Introduction. California: Mayfield Publishing Company Mountain View, 94041.

McCue, H. \& Kourouche, F. (2010). The Identity of the 'Australian Muslim Woman' in Sport and Recreation. In S. Akbarzadeh (Ed.), Challenging Identities: Muslim Women in Australia, pp.130-158.

Miloch, K. S., Pedersen, P. M., Smucker, M. K. \& Whisenant, W. A. (2005). The Current State of Women Print Journalists: An Analysis of the Status and Careers of Females in Newspapers Sports Departments. Public Organization Review, vol.5:3, pp.219-232.

Parry, L. \& Karam, B. 2001. Feminist Media Theory. Media Studies: Institutions, Theories, and Issues, vol.1, p.383.

Raheel, N. (2012). Pakistan Swimmers Smash National Records. The Express Tribune, November 19r retrieved from: http://tribune.com.pk/story/467687/pakistanswimmers-smash-national-records/

Raheel, N. (2013a). Naseem Hameed: The 'Queen of Tracks' with Nerves of Steel. The Express Tribune, March 3, retrieved from: http://tribune.com.pk/story/ 515049/naseem-hameed-the-queen-of-tracks-with-nerves-of-steel/

Raheel, N. (2013b). Female Swimmer Sets New Record. The Express Tribune, July 3, retrieved from: http://tribune.com.pk/story/571711/female-swimmer-sets-new-record/

Rahman, T. (2000). Language, Education, and Culture. Oxford University Press.

Reuters. (2011). Pakistan Give Women Cricketers Central Contracts for the First Time. Dawn, May 18, retrieved from: http://www.dawn.com/news/629654/pakistangive-women-cricketers-central-contracts-for-the-first-time

Rogers, E.M. \& Dearing, J.W. (1988). Agenda-Setting Research: Where has it been? Where is it going? In: Anderson, J.A. (Ed.). Communication Yearbook 11 (555594). Newbury Park, CA: Sage. 
Sage, M. \& Furst, D. M. (1994). Coverage of Women's Sports in Selected Newspapers. Perceptual and Motor Skills, vol.78:1, pp.295-296.

Sports Reporter. (2014). Double Glory for Sidra. Dawn, May 29, retrieved from: http://www.dawn.com/news/1109160/double-glory-for-sidra

Stockard, J. \& Johnson, M. M. (1980). Sex Roles: Sex Inequality and Sex Role Development. Englewood Cliffs, New Jersey: Prentice-Hall, Inc.

Talbot, M. M., Atkinson, K. \& Atkinson, D. (2003). Language and Power in the Modern World. Edinburgh University Press.

Trudgill, P. (1980). Sociolinguistics: An Introduction. England: Penguin Books Ltd.

Van Ingen, C. (2003). Geographies of Gender, Sexuality and Race Reframing the Focus on Space in Sport Sociology. International Review for the Sociology of Sport, vol.38:2, pp.201-216.

Van Zoonen, L. (1994). Feminist Media Studies, Sage, vol.9.

Vertinsky, P. (2004). Locating a 'Sense of Place': Space, Place and Gender in the Gymnasium. Sites of Sport: Space, Place, Experience, pp.8-24.

Wensing, E. H. \& Bruce, T. (2003). Bending the Rules Media Representations of Gender During an International Sporting Event. International Review for the Sociology of Sport, vol.38:4, pp.387-396.

Whorf, B. L. (1940). Science and linguistics (pp. 207-219). Bobbs-Merrill.

Young, I. M. (1990). Throwing Like a Girl and Other Essays in Feminist Philosophy and Social Theory (p. 13). Bloomington: Indiana University Press.

Qaisar Khan is an Assistant Professor in the Department of English, University of Malakand.

Maria B. Shahid is Lecturer in the Department of English, Fatima Jinnah Women University.

Sohni Ihsan is Research Scholar in the Department of English, Fatima Jinnah Women University. 